\title{
Toplumun Sığınmacı Bireylerle İlgili Sosyal Mesafe ve Kaygi Durumlarının Belirlenmesi ${ }^{1}$
}

\author{
DOI: 10.26466/opus.545074 \\ * \\ Gülay Tașdemir Yiğitoğlü ${ }_{-}^{*}$ Bilgin Kıray Vural** \\ * Dr Öğr. Üyesi, Pamukkale Üniversitesi, Sağlık Bil. Fak. Hemşirelik Böl., Kınıklı/ Denizli/Türkiye \\ E-Posta: gyigitoglu@pau.edu.tr ORCID: 0000-0002-8075-7155 \\ ** Dr Öğr. Üyesi, Pamukkale Üniversitesi, Sağlık Hizmetleri MYO., Kınıklı/ Denizli/ Türkiye \\ E-Posta: bvural@pau.edu.tr \\ ORCID: 0000-0002-2136-8192
}

$\ddot{O} z$

Bu çalışma toplumun sığınmacı bireylerle ilgili sosyal mesafe ve kaygı durumlarını incelemek amacıyla tanımlayıcı ve kesitsel araştırma deseninde tasarlanmıştır. Araştırmanın evrenini Denizli'de yaşayan 18 yaş ve üzeri bireyler oluşturmuştur. Örnekleme yöntemlerinden gelişigüzel örnekleme yöntemi kullanılmıştır. Çalışmada sosyodemografik değişkenleri ölçen veri toplama formu, Gruplararası Kaygı Ölçeği (GKÖ) ve Sosyal Mesafe Ölçeği (SMÖ) kullanılmıştır. Verilerin analizinde; verilerinin sayı ve yüzde dağılımları, Student t testi, Varyans Analizi kullanılmışıtır. Araştırmanın örneklemini 1709 kişi oluşturmuştur. Katıllımclların büyük çoğunluğunun (\%83.5) kendisini Türk olarak, geriye kalanların da (\%16.5) Çerkez, Çeçen, Kürt, Boşnak, Muhacir, Laz, Arap olarak ifade ettiği belirlenmiştir. GKÖ incelendiğinde, kadınların erkeklere, kendisini Türk olarak ifade edenlerin diğer etnik kökenden olanlara oranla daha kaygılı oldukları belirlenmiş olup, istatistiksel olarak farkın anlamlı olduğ u saptanmıştır $(p<0.05)$. SMÖ incelendiğinde ise; kadınların, ilköğretim ve orta öğretim mezunlarının ve kendisini Türk olarak ifade edenlerin sığınmacılara daha mesafeli oldukları belirlenmiştir ( $p<0.05)$. Ayrıca bireylerin GKÖ ve SMÖ puan ortalamaları arasında orta düzeyde, doğru yönde ve pozitif bir iliş̧inin olduğu istatistiksel olarak belirlenmiştir ( $r=.60, p<.01)$. Araştırmaya katılan bireylerin, sı̆̆ınmacılara yönelik duygu ve düşüncelerinin olumsuz, önyargılı ve ayrımcı eğilim içinde olduğu saptanmıştır.

Anahtar Kelimeler: Gruplararası kaygı, sığınmacı, sosyal mesafe

\footnotetext{
${ }^{1}$ Bu çalışma, 11-14 Mayıs 2017 Denizli'de IV. International Eurasian Educational Research Congress'de sözlü bildiri olarak sunulmuştur.
} 


\title{
Determination of Social Distance and Anxiety Situations of the Society about Asylum Seekers
}

\begin{abstract}
This study uses a descriptive and cross-sectional study design to determination of social distance and anxiety situations of the society about asylum seekers. The research population consisted of individuals older than 18 living in Denizli. A random sampling method was used. To collect data, the following tools were used: a questionnaire to collect socio-demographic information, the Intergroups Anxiety Scale (IAS) and the Social Distance Scale (SDS). Statistical analysis was conducted to examine the distributions and proportions of attitudes in the sample, as well as student $t$ testing, analysis of variance. The number of people who involved in this survey was 1709. A large majority of the participants (83.5\%) described themselves as Turkish; the remaining 16.5\% described themselves as Circassian, Chechen, Kurdish, Bosnian, Laz or Arab. The IAS total mean score was found to be $18.60 \pm 6.62$ while the SDS total mean score was 19.96 \pm 7.82 . When IAS is examined, it is determined that women are more anxious than males who express themselves as Turks compared to other ethnic origin, and the statistical difference is significant. When SDS was examined, it was determided that women, primary school and secondary school graduates and people describing themselves as Turkish have to be distant to asylumseekers ( $p$ <.05). In addition, it was determined statistically that there is a medium level and positive correlation between individuals' IAS and SDS point averages $(r=.60, p<.01)$. That is, the emotion and thought of individuals participating in the survey towards asylum-seekers were found to be have negative, prejudiced and discriminatory tendency.
\end{abstract}

Keywords: Intergroup anxiety, asylum-seeker, social distance. 


\section{Giriş}

Mülteci kavramı 1951 Cenevre Sözleşmesine göre; vatandaşı olduğu ülkeden başka bir ülkede bulunan ve ırkı, dini, tabiiyeti nedeniyle veya belirli bir sosyal grubun ya da siyasi görüşün bir parçası olduğu için kötü muamele göreceği hakkında ciddi korkuları olan, bu nedenle de kendi ülkesine dönemeyen ya da dönmek istemeyen kişidir. Sığınmacı ise, sığındığı ülkeden mülteci olarak koruma talep eden ve başvurusu henüz karara bağlanmamış kişiler için kullanılmaktadır. Aynı zamanda henüz başvuru yapmamış veya başvurusu hakkında cevap bekleyen kişiler de sığınmacı olarak tanımlanmaktadır. Bir anlamda sığınmacılık bir süreç iken mültecilik ise bir statüdür, yani sonuçtur (Göç İdaresi Genel Müdürlüğü [GIGM], 2016; Urk, 2010). Bu tanımlamalara göre ülkeye mecburi nedenlerle göç eden herkese sığınmacı kavramı uygun görülmüş ve bu çalışmada sığınmacı terimi kullanılmıştır.

Uluslararası göç, ekonomi, sosyal yapı ve sosyo-politik durumları etkileyerek insanlık tarihini değiştiren en önemli etkenlerdendir. En kalabalık uluslararası göçü Suriye'deki savaştan kaçan halk oluşturmuştur. 4 milyon Suriyeli başta Türkiye olmak üzere, Lübnan, Ürdün ve Irak'a sığınmış ve iltica talebinde bulunmuştur (Chronicle, 2015). Coğrafi konumu ve vize uygulamaları sebebiyle sığınmacılar için çekici bir konumda bulunan Türkiye yaklaşık 3.3 milyon Suriyeli'ye kamp içi ve kamp dış1 olmak üzere ev sahipliği yapmaktadır. Bununla birlikte Türkiye'de Afganistan (157000), Irak (152000), İran (33000), Somali (4000) ve diğer tabiiyetler (10000) olmak üzere toplam 3.7 milyon sığınmacı bulunmaktadır (UNHCR, 2017). Sığınmacı akını, özellikle sınır illerinin demografik yapısını etkilemiş ve bu illerin nüfusunu yaklaşık iki katına çıarmıştır. Bu sürecin ilk başında Türkiye krizin oldukça hızlı bir şekilde çözüleceği ve sığınmacıların ülkelerine dönüş yapacağı beklentisi içindeydi. Fakat Suriye'deki iç savaş devam etmiş ve başka ülkelere sığınan Suriyelilerin geri dönüş ihtimalleri ise oldukça azalmıştır (Karakaş, 2014).

Sığınmacıların uzun süreden beri Türkiye'de bulunmaları toplumda farklı bakış açılarının oluşmasına sebep olmuştur. Toplumda sığınmacılara yönelik; misafirperverlik, acıma ve çok kültürlülügün iyi olduğuna yönelik olumlu; toplumun yapısının bozulduğu, işsizlik, kira fiyatlarının artması gibi ekonomik koşulların kısıtlılı̆̆ına sebep 
olduklarına, sağlık ve eğitim alanında sorunlar oluşturduklarına yönelik olumsuz bakış açıları da bulunmaktadır (Kesgin, 2014). Bireyler genellikle sığınmacılarla ilgili bu olumlu ya da olumsuz bakış açılarını tecrübelerinden, okuduklarından, izlediklerinden ya da duyduklarından yola çıkarak oluşturmaktadırlar (Güngör, 2014; Mercan Uzun ve Bütün, 2016).

Göç alan toplumların sığınmacılara yönelik davranışları incelendiğinde; toplumların sığınmacilara büyük oranda kültürel mesafe koydukları, demografik açıdan kaygı duydukları, özellikle iş kaybetme ve gelir kaybı kaygısı yaşadıkları, ev fiyatlarının yükselmesine bağlı olarak ekonomik kaygı duydukları belirlenmiştir. Toplumlarda genelde, sığınmacıların sosyal hizmetlere yük getirdiği ve kamu hizmetlerinde (eğitim, sağlık gibi) aksamalara neden olduğu düşüncesi hakimdir. Bunların dışında sıklıkla hastalıkların ve suçun nedeni olarak görülmekte ve dolayısıyla sığınmacılara karşı güvensizlik duyulmaktadırlar. Bu bakış açısı sığınmacıların toplumsal uyumunu güçleştirmektedir (Erdoğan, 2014; Karaca ve Doğan, 2014; Oytun ve Gündoğar, 2015; Yıldız, 2013; Zencir ve Davas, 2014). Bu da toplumun sığınmacılara yönelik sosyal mesafe oluşturmasına ve onlarla etkileşimde bulunurken sosyal kaygı oluşabilmesine neden olabilmektedir.

Sosyal mesafe, belirli bir sosyal sinıfa ait olan herhangi bir ferdin, diğer siniflarla ve o siniflara mensup bulunan gruplar ve fertlerle olan hiyerarşik ilişkilerini, bir nüfus içindeki sınıfların birbirleri ile olan ilişkilerini ve belirli nüfusların aralarındaki sosyal farklılık ilişkilerini gösteren bir kavramdır (Bogardus, 1925). Sosyal mesafe sosyal psikolojide; ırk, din, milliyet gibi farklı sosyal gruplardan üyelerin birbirlerini kabul veya reddetme derecesidir. Sosyolojik olarak sosyal mesafe, sosyal gruplarin mahremiyet sınırlarını hangi mesafede çizmeyi istekli olduklarını gösteren, toplumsal değişkenlere ya da ağlara dayalı benzerlik ya da yakınlık ve uzaklıktır (Marshall, 1999; Magee ve Smith, 2013). Gruplararası kaygı ise, olumsuz duygulanım durumu olarak diğer grupla yaşanacak bir etkileşimde reddedilme, utanç verici duruma düşürülme hissi, huzursuzluk gibi hoş olmayan deneyimleri yaşama olasılığından kaynaklanan duygu olarak tanımlanmaktadır (Stephan ve Stephan, 1985).

Sığınmacılara yönelik sosyal mesafe koymak ve iletişim kurarken onlara karşı kaygılı olmak sı̆̆ınmacıların yalnızlaşmasına ve önyargıların ortaya çıkmasına sebep olabilmektedir. Toplumun bu kişileri kendinden 
uzak tutması ve önyargılı davranması, sığınmacılarda problemli davranışlara ve sağlık sorunlarına neden olacaktır. Ayrıca bu durum sığınmacılarda anksiyete bozuklukları, depresyon, travma sonrası stres bozukluğu, öfke patlamaları, şiddet eğilimleri gibi psikososyal ve psikiyatrik sorunların ortaya çıkmasını hızlandırabilecektir. Ülkemizde sayısı gitgide artan sığınmacılara yönelik bütüncül sağlik hizmetlerin planlanması ve uygulanması için, bir arada yaşayan toplum bireylerinin ve onların birbirleriyle ilgili duygu ve düşüncelerinin tanınması ve bilinmesinin oldukça önemli olduğu düşünülmektedir.

$\mathrm{Bu}$ çalışmayla bireylerin gruplararası kaygı durumu ve sosyal mesafeleri ölçülerek sığınmacı bireylerle ilgili somut veriler elde edilecektir. Uzun süre Türkiye'de kalacağı düşünülen bu bireylere yönelik araştırmaya katılanların ne düşündüğü ve bu bireylerle birlikte daha sağlıklı ve mutlu yaşanılabilir olması için, daha olumlu tutumların beslenmesi konusunda neler yapılması gerektiği hakkında bilgi verecek bir çalışma olacağı öngörülmektedir. Ek olarak toplumun sığınmacı bireylerle ilgili duygu ve düşüncelerinin nasıl olduğuna yönelik geniş örnekleme sahip çalışmaların çok sık rastlanılamadığı ve bu açıdan da önemli bir çalışma olduğu tahmin edilmektedir.

Bu çalışmanın amacı toplumun sığınmacı bireylerle ilgili sosyal mesafe ve kaygı durumlarını belirlemektir. Amaç kapsamında araştırmanın hipotezleri aşağıdaki gibidir:

- H1: Çalışmaya alınan bireylerin genel kaygı ve sosyal mesafe puan ortalamaları düşüktür.

- H2: Çalışmaya alınan bireylerin sosyodemografik özelliklerinin gruplararası kaygı düzeyine ve sosyal mesafeye etkisi vardır.

- H3: Çalışmaya alınan bireylerin gruplararası kaygı düzeyi arttıkça sosyal mesafeleri artar.

\section{Yöntem}

Bu çalışma toplumun sığınmacı bireylerle ilgili sosyal mesafe ve kaygı durumlarını belirlemek amacıyla tanımlayıcı ve kesitsel araştırma deseninde tasarlanmıştır. Araştırmanın verileri Haziran 2016-Eylül 2016 tarihleri arasında toplanmıştır. Araştırma merkezi Denizli'dir. 


\section{Evren ve Örneklem}

Araştırmanın evrenini Denizli' de yaşayan 18 yaş ve üzeri bireyler oluşturmuştur. Çalışmada gelişigüzel örneklem yöntemi kullanılmış ve veriler anketörler tarafından toplanmıştır. Anket formu uygulanmadan önce bireylere araştırmanın amacı ve formların içeriği hakkında açıklamalarda bulunup, katılımları için onam formunu okumaları ve onaylamaları istenmiştir.

Çalışmaya alınanların okuma yazma biliyor olması, 18 yaş ve üzeri olması, çalışmaya katılmayı kabul etmesi, zeka geriliğinin olmaması, iletişimi önemli düzeyde etkileyecek oranda görme, işitme ve bilişsel yeti kaybının olmaması araştırmanın dahil olma ve dışlama kriterlerini oluşturmuştur.

\section{Araştırmanın Etik Yönü}

Araştırma kapsamına alınanların sözel onamları alınmıştır. Pamukkale Üniversitesi Girişimsel Olmayan Klinik Araştırmalar Etik Kurulu'ndan 17.06.2016 tarihinde 60116787/38135 sayılı karar ile yazılı izin alınmıştır.

\section{Veri Toplam Araçları}

\section{Veri Toplama Formu}

Araştırmacılar tarafından hazırlanmış olan bu formda çalışmaya alınan bireylerin yaş, cinsiyet, meslek, eğitim durumu ile ilgili sosyodemografik bilgiyi ortaya çıkaran sorular bulunmaktadır.

Gruplararası Kaygı Ölçeği (GKÖ): Katılımcıların sosyal etkileşimlerinde diğer grupla olan temasları sırasında kendilerini nasıl hissettiklerini ve kaygılarını değerlendirmeleri için yedi maddeden oluşan sıfat çiftleri kullanılmıştır. GKÖ'yü oluşturan sıfat seçiminde literatürde daha önce kaygı durumunu değerlendirmek üzere kullanılmış sıfatlardan ve ifadelerden yararlanılmıştır (Stephan ve Stephan, 1996). Sıfatlar seçilirken katılımcıların iki grubun birbiri ile sosyal ilişkilerini düşündükleri anda hissedebileceği duyguları tanımlamaya yönelik sıfatlar (örneğin; değersiz, 
tehdit altında gibi) yerleştirilmiştir. GKÖ'de semantik farklılaştırma yöntemi gereği ifadelerin karşıt formları arasına birbirlerinden eşit uzaklıkta duran 1'den 5'e kadar numaralandırma verilmiş ve katılımcılardan diğer grupla sosyal ilişkiyi yaşarken hissettikleri duyguları en iyi tanımlayan yakın rakamın üzerine çarpı işareti koymaları istenmiştir. Bu işleme göre katılımcilar duygu durumlarını 5'li likert tipi derecelendirme üzerinde değerlendirmiştir. Bu ölçekte değerlendirme olumsuzdan olumluya doğru olduğu için analizlerde verilen ortalamalarda düşük değer olumsuz değerlendirmeyi, yüksek değer ise olumlu değerlendirmeyi yansıtmaktadır. Ölçekten elde edilen en yüksek puan 35'dir. Ölçeğin Güler (2013) tarafından yapılan Cronbach Alfa güvenirlik katsayısı .94'tür. Yapılan bu araştırmada GKÖ Cronbach Alfa .76 olarak saptanmıştır.

Sosyal Mesafe Ölçeği: Sosyal grupların, birbirlerini algılanan yakınlık derecesi (komşuluk, arkadaşlık, evlilik) ile değerlendirme ve onaylamasına işaret eden sosyal mesafe tanımlaması Bogardus (1925) tarafından öne sürülmüştür. Ölçek maddeleri, Güler (2013) tarafından Bogardus'un (1925) sosyal mesafeye ilişkin tanımlamaları dikkate alınarak oluşturulmuştur. Ölçek, farklı din, etnik köken ve ırktan gelen insanların diğer gruptan olan kişi ya da kişilerle komşuluk etme, arkadaş olma ya da evlenme gibi konularda ne derece kabul gördüğünü ölçmeyi amaçlamaktadır.

Gruplararası sosyal mesafeyi ölçmek amacıyla toplam sekiz maddeden oluşan ölçekte katılımcılardan her bir maddede öne sürülen fikir cümlesini 5'li likert tipi derecelendirme üzerinden "Kesinlikle katılmıyorum", "Kısmen katılmiyorum", "Kararsızım”, “Kısmen katılıyorum" ve "Tamamen katılıyorum" seçeneklerinden kendisini en iyi temsil eden bir seçeneği çarpı işareti ile işaretlemesi istenmektedir. Bu ölçekte değerlendirme olumsuzdan olumluya doğru olduğu için analizlerde verilen ortalamalarda düşük değer olumsuz değerlendirmeyi, yüksek değer ise olumlu değerlendirmeyi yansıtmaktadır. Ölçekten yüksek puan almak diğer kökenden olanlarla yakın mesafede bulunmaya işaret etmektedir. Ölçekten elde edilen en yüksek puan 40'tır. Ölçeğin Güler (2013) tarafından yapılan araştırmada güvenirlik katsayısı Cronbach Alfa .90 'dır. Yapılan bu araştırmada SMÖ Cronbach Alfa .87 olarak saptanmıştır. 


\section{Verilerin Analizi}

Verilerin analizinde SPSS 15.0 paket programı kullanılmış ve sayı, yüzde dağılımları, Student $t$ testi ve Varyans analizi kullanılmıştır.

\section{Bulgular}

\section{Bireylere İlişkin Sosyodemografik Özellikler}

Table 1. Bireylere ilişkin sosyodemografik özellikler

\begin{tabular}{ll}
\hline Sosyodemografik özellikler & $\mathbf{n}(\%)$ \\
\hline Yaş & \\
\hline 19 yaş ve $\downarrow$ & $182(10.6)$ \\
$20-39$ & $1066(62.4)$ \\
$40-59$ & $403(23.6)$ \\
60 ve $\uparrow$ & $58(3.4)$ \\
\hline Cinsiyet & \\
\hline Kadın & $830(48.6)$ \\
Erkek & $879(51.4)$ \\
\hline Eğitim & \\
\hline Okur-yazar & $44(2.6)$ \\
Ilköğretim & $400(23.4)$ \\
Ortaöğretim & $589(34.5)$ \\
Üniversite & $676(39.5)$ \\
\hline Gelir durumu & \\
\hline İyi & $327(19.1)$ \\
Orta & $1145(67.0)$ \\
Kötü & $237(13.9)$ \\
\hline Çalışma durumu & $1000(58.5)$ \\
\hline Evet & $709(41.5)$ \\
Hayır & \\
\hline Etnik Köken (n=1664) & $1427(85.8)$ \\
\hline Türk & $237(14.2)$ \\
Diğer (Çerkez, Çeçen, Kürt, Boşnak, Muhacır, Laz, Arap) \\
\hline En uzun yaşadığı yer & $1303(76.2)$ \\
\hline Kentsel & $406(23.8)$ \\
Kırsal & $\mathbf{1 7 0 9 ( 1 0 0 . 0 )}$ \\
\hline Toplam &
\end{tabular}

Bu araştırmada 1709 kişi yer almış ve bunların yaş aralığ 18-88 olarak saptanmıştır. Katılımcıların \% 48.6'sı kadın, \%51.4'ü erkektir. Yaş ortalamaları 33.23 \pm 11.80 olup, yarısından fazlası (\%62.4) 30-39 yaş arasındadır. 
Araştırmaya katılanların \%34.5'i lise ve dengi okul, \%36.3'ü üniversiteyüksekokul mezunlarıdır ve \%67.0'si gelir durumunu orta gelir olarak ifade etmiştir. Gelir getiren işte çalışanların oranı \%58.5 olup, \%45.6's1 aylık kazancını 1400-4999 TL arasında ve \%35.1'i de 1399 TL ve altında olduğunu belirtmiştir. Katılımcıların etnik köken olarak büyük çoğunluğunun (\%83.5) kendisini Türk, geriye kalanların da (\%16.5) Çerkez, Çeçen, Kürt, Boşnak, Muhacir, Laz, Arap olarak tanımladığı görülmektedir (Tablo 1).

\section{Bireylerin Sosyodemografik Özelliklerine Göre Gruplararası Kaygı ve Sosyal Mesafe Ölçeği Madde Puan Ortalamaları}

Araştırmaya katılan bireylerin GKÖ madde toplam puan ortalaması 18.60 \pm 6.62 olup, madde puan ortalaması da $2.65 \pm .94^{\prime}$ tür. GKÖ puan ortalamaları yükseldikçe bireylerin gruplararası kaygısının düşük olduğu, puan ortalaması azaldıkça kaygılarının yüksek olduğu anlamına gelmektedir. Yapılan bu çalışmada bireylerin kaygı puanları orta düzeydedir.

Çalışmada cinsiyetin gruplararası kaygıya etkisinin istatistiksel olarak anlamlı olduğu ( $\mathrm{t}=-3.074, \mathrm{p}=$.002) saptanmıştır (Tablo 2). Erkeklere göre, kadınların daha kaygılı olduğu görülmektedir. Kadınlar sığınmacılarla iletişimde daha uzak, eşit olmayan, kuşkulu, tehdit altında ve gergin olduklarını/olacaklarını ifade ederken, erkekler daha pozitif ifadelerde bulunmuştur.

Çalışmaya alınanların etnik kökenin gruplararası kaygıya etkisinin anlamlı ( $\mathrm{t}=-5.602, \mathrm{p}=.001$ ) olduğu belirlenmiştir (Tablo 2). Yapılan ileri analizde kendisini Türk olarak ifade edenlerin diğer etnik kökenlerden olanlara oranla sığınmacılara negatif (uzak, eşit olmayan, değersiz, kuşkulu, kaygılı, tehdit altında, gergin), diğer etnik kökende olduklarını belirtenlerin pozitif ifadelerde bulundukları (eşit, samimi, değerli, güvenilir, kaygısız, güven verici, rahat) belirlenmiştir.

$\mathrm{Bu}$ çalışmada yaşın $(\mathrm{p}=.157)$, eğitimin $(\mathrm{p}=.574)$, gelirin $(\mathrm{p}=.555)$, çalışma durumunun $(\mathrm{p}=.486)$ ve en uzun yaşanılan yerin $(\mathrm{p}=.834)$ gruplararası kaygıya etkisinin olmadığı saptanmıştır. 
Tablo 2. Bireylerin sosyodemografik özelliklere göre GKÖ madde puan ortalamalarının dă̆glımı ( $n=1709)$

\begin{tabular}{lll}
\hline Sosyodemografik özellikler & GKÖ & p \\
\hline Yaş & & $\mathrm{F}=1.741$ \\
\hline 19 yaş ve $\downarrow$ & $2.79 \pm .88$ & $\mathrm{p}=.157$ \\
$20-39$ & $2.65 \pm .96$ & \\
$40-59$ & $2.60 \pm .87$ & \\
60 ve $\uparrow$ & $2.67 \pm 1.16$ & \\
\hline Cinsiyet & & $\mathrm{t}=-3.074$ \\
\hline Kadın & $2.58 \pm .93$ & $\mathrm{p}=.002$ \\
Erkek & $2.72 \pm .92$ & \\
\hline Eğitim & & \\
\hline Okur-yazar & $2.74 \pm 1.02$ & $\mathrm{~F}=.664$ \\
Illköğretim & $2.60 \pm .93$ & $\mathrm{p}=.574$ \\
Ortaöğretim & $2.68 \pm .95$ & \\
Üniversite & $2.65 \pm .93$ & $\mathrm{~F}=.589$ \\
\hline Gelir durumu & & $\mathrm{p}=.555$ \\
\hline İyi & $2.68 \pm .92$ & \\
Orta & $2.66 \pm .93$ & $\mathrm{t}=-.697$ \\
Kötü & $2.59 \pm 1.04$ & $\mathrm{p}=.486$ \\
\hline Çalışma durumu & & $\mathrm{t}=-5.602$ \\
\hline Evet & $2.66 \pm .94$ & $\mathrm{p}=.001$ \\
Hayır & $2.69 \pm .91$ & \\
\hline Etnik köken & & $\mathrm{p}=.834$ \\
\hline Türk & $2.60 \pm .93$ & \\
Diğer(Çerkez,Çeçen, Kürt, & $2.97 \pm .90$ & \\
Boşnak, Muhacr, Laz, Arap) & & \\
\hline En uzun yaşadığ1 yer & $2.66 \pm .94$ & \\
\hline Kentsel & $2.64 \pm .94$ & \\
Kırsal & & \\
\hline
\end{tabular}

Araştırmaya katılan bireylerin SMÖ madde toplam puan ortalaması $19.96 \pm 7.82$ olup, madde puan ortalaması da $2.49 \pm .97$ olarak belirlenmiştir. Bireylerin SMÖ puan ortalamaları arttıkça sığınmacılara yönelik sosyal mesafelerinin az olduğu, puan ortalamaları azaldıkça sığınmacılara yönelik sosyal mesafelerinin çok olduğu belirtilmektedir. Bu çalışmada bireylerin SMÖ puan ortalamaları düşüktür.

Yapılan çalışmada cinsiyetin, sosyal mesafeye etkisinin olduğu ( $t=-$ 2.492, $\mathrm{p}=.013$ ) istatistiksel olarak belirlenmiştir (Tablo 3). "Sığınmacı olanlarla sosyal bir etkinliğe katılırım", "Alışverişimi sığınmacı olanların mağazalarından yaparım", "Sığınmacı olanlarla kapı komşusu olmayı 
isterim", "Sı̆̆ınmacı olanlarla aynı mahallede yaşamayı isterim", "Eşi$\mathrm{min} /$ nişanlımın/sevgilimin/çocuğumun sığınmacı biriyle arkadaşlığını kabul ederim", "Sığınmacılardan kız (gelin) alırım”, "Sığınmacılardan erkek (damat) alırım", "Sığınmacı biriyle evlenirim" şeklindeki ifadelere erkeklerin kadınlara oranla sosyal mesafelerinin daha az olduğu saptanmiştır.

Çalışmaya alınanların eğitim düzeyinin sosyal mesafe puanına etkisinin istatistiksel olarak anlamlı olduğu bulunmuştur $(\mathrm{F}=2.982, \mathrm{p}=$ .030) (Tablo 3). Yapılan Post Hoc testte (Tamhane) ortaöğretim mezunları ve üniversite mezunlarındaki fark düşündürücüdür $(p=.037)$. Verilen yanıtların yüzde değerleri incelenmiş olup, aşağıda eğitim düzeyine göre bireylerin SMÖ’ye verdikleri yanıtlara yönelik en yüksek oranlar (olumluolumsuz) verilmiştir. Sosyal bir etkinliğe katılmak isteyenler okuryazar olan grupta (\%47.8), istemeyenler ise orta öğretim grubunda (\%49.0) fazladır. Alışverişini sığınmacı olanların mağazalarından yapabileceğini ifade edenler içerisinde en yüksek oran (\%40) ile üniversite mezunları, yapmayacağını belirtenlerde en yüksek oran (\%50) okuryazar olanlardır. Komşu olmayı isteyenler (\%29.5) okuryazar olanlar, istemeyenler ise (\%51.3) ilköğretim mezunlarıdır. Aynı mahallede yaşamayı isteyenler (\%29.5) okuryazar olanlar, istemeyenler (\%47.3) orta öğretimi bitirenlerdir. Yakınlarının sığınmacılarla arkadaşlı̆̆ını onaylayanlar (\%28.1) en fazla üniversite mezunları, onaylamayanlar ise (\%53.8) orta öğretim mezunlarıdır. Sığınmacılardan gelin almak isteyenler (\%34.1) okuryazar olanlar, istemeyenler (\%62.1) orta öğretimi bitirenlerdir. Sığınmacılardan damat isteyenler en yüksek oranda okuryazar olanlar (\%20.5), istemeyenler ise (\%66.1) orta öğretimi bitirenlerdir. Sığınmacilarla evlenirim ifadesini en yüksek oranda onaylayanlar okuryazar olanlardır (\%22.7), evlenmek istemeyenler ise en yüksek oranda orta öğretim mezunlarıdır (\%66.1).

Yapılan bu araştırmada etnik kökenin sosyal mesafede etkisinin önemli olduğu saptanmıştır ( $\mathrm{t}=-5.167, \mathrm{p}=.001)$. Etnik kökenini Türk olarak ifade edenlerin sosyal mesafe puanlarının, diğer etnik kökenlere oranla oldukça düşük (olumsuz) olduğu görülmektedir (Tablo 3). 
Tablo 3. Bireylerin sosyodemografik özelliklere göre SMÖ madde puan ortalamalarııın dă̆ılımı (n=1709)

\begin{tabular}{|c|c|c|}
\hline Sosyodemografik özellikler & SMÖ & p \\
\hline \multicolumn{3}{|l|}{ Yaş } \\
\hline 19 yaş ve $\downarrow$ & $2.56 \pm .97$ & $\mathrm{~F}=2.406$ \\
\hline 20-39 & $2.47 \pm .98$ & $\mathrm{p}=.066$ \\
\hline $40-59$ & $2.54 \pm .92$ & \\
\hline 60 ve $\uparrow$ & $2.21 \pm 1.07$ & \\
\hline \multicolumn{3}{|l|}{ Cinsiyet } \\
\hline Kadın & $2.43 \pm .92$ & $\mathrm{t}=-2.492$ \\
\hline Erkek & $2.55 \pm 1.02$ & $\mathrm{p}=.013$ \\
\hline \multicolumn{3}{|l|}{ Eğitim } \\
\hline Okur-yazar & $2.58 \pm .93$ & \\
\hline İlköğretim & $2.45 \pm .91$ & $F=2.982$ \\
\hline Ortaöğretim & $2.42 \pm 1.00$ & $\mathrm{p}=.030$ \\
\hline Üniversite & $2.57 \pm .98$ & \\
\hline \multicolumn{3}{|l|}{ Gelir durumu } \\
\hline İyi & $2.46 \pm .95$ & $\mathrm{~F}=2.697$ \\
\hline Orta & $2.53 \pm .95$ & $\mathrm{p}=.068$ \\
\hline Kötü & $2.37 \pm 1.11$ & \\
\hline \multicolumn{3}{|l|}{ Çalışma durumu } \\
\hline Evet & $2.48 \pm .97$ & $\mathrm{t}=-.551$ \\
\hline Hayır & $2.51 \pm .98$ & $\mathrm{p}=.582$ \\
\hline \multicolumn{3}{|l|}{ Etnik köken } \\
\hline Türk & $2.44 \pm .96$ & $\mathrm{t}=-5.167$ \\
\hline $\begin{array}{l}\text { Diğer(Çerkez,Çeçen, Kürt,Boşnak, } \\
\text { Muhacır, } \\
\text { Laz, Arap) }\end{array}$ & $2.80 \pm 1.00$ & $\mathrm{p}=.001$ \\
\hline \multicolumn{3}{|l|}{ En uzun yaşadığı yer } \\
\hline Kentsel & $2.50 \pm .98$ & $\mathrm{t}=.232$ \\
\hline Kırsal & $2.49 \pm .97$ & $\mathrm{p}=.817$ \\
\hline
\end{tabular}

Çalışmada, "Sığınmacı olanlarla sosyal bir etkinliğe katılırım", Alışverişimi sığınmacı olanların mağazalarından yaparım", "Sığınmacı olanlarla kapı komşusu olmayı isterim", "Sığınmacı olanlarla aynı mahallede yaşamayı isterim", "Eşimin/nişanlımın/sevgilimin/çocuğumun sığınmacı biriyle arkadaşlığını kabul ederim", "Sığınmacılardan kız (gelin) alırım", "Sı ğınmacılardan erkek (damat) alırım", "Sı̆̆ınmacı biriyle evlenirim" şeklindeki ifadeler incelendiğinde Türk olduğunu ifade edenlere göre farklı etnik kökenlerden gelenlerin daha olumlu düşüncelere sahip olduğu belirlenmiştir. 
Bu çalışmada yaşın $(\mathrm{p}=.066)$, gelirin $(\mathrm{p}=.068)$ ve çalışma durumunun $(\mathrm{p}=.582)$, en uzun yaşanılan yerin $(\mathrm{p}=.817) \mathrm{SMÖ}^{\prime}$ ye etkisinin istatistiksel olarak anlamlı olmadığı belirlenmiştir (Tablo 3).

Çalışmaya katılan bireylerin GKÖ ve SMÖ puan ortalamaları arasında orta düzeyde, doğru yönde ve pozitif bir ilişkinin olduğu istatistiksel olarak saptanmıştır $(\mathrm{r}=.60, \mathrm{p}<.05)$.

Bu bulgular doğrultusunda bireylerin GKÖ ve SMÖ puan ortalamalarının düşük olduğu; sosyodemografik özelliklerinin gruplararası kaygı düzeyine ve sosyal mesafeye etkisinin olduğu; gruplararası kaygı düzeyi arttıkça sosyal mesafelerinin arttığ saptanmış ve H1, H2, H3 hipotezleri desteklenmiştir.

\section{Tartışma}

Çalışmaya katılan bireylerin GKÖ madde toplam puan ortalamaları $18.60 \pm 6.62$ 'dir. GKÖ puan ortalamaları yükseldikçe bireylerin gruplararası kaygısının düşük olduğu, puan ortalaması azaldıkça kaygılarının yüksek olduğu anlamına gelmektedir. Yapılan bu çalışmada bireylerin kaygı puanlarının orta düzeyde olduğu görülmektedir. Bu da bireylerin sığınmacı kişilerle etkileşimde bulundukları durumda kaygılı olabileceklerini göstermektedir. Erdoğan'ın (2014) yaptığı çalışmada da toplumun sığınmacılarla etkileşimde bulunurken kaygılı oldukları belirlenmiştir. Yine Deniz'in (2015) yapmış olduğu bir çalışmada sığınmacıların göç ettikleri yerlerde konut yetersizliğine neden olmaları, bunun ortaya çıkardığı kiralık ev bulma sorunları ve kira fiyatlarında meydana gelen artışlar nedeniyle, özellikle kirada olan halkın sığınmacılara yönelik endişelerinin ve önyargılarının artmasına yol açtığı ve onlarla etkileşimde bulunmak istemedikleri ifade edilmektedir.

Olumlu ya da olumsuz olsun duygular, ilişkileri şekillendirmekte oldukça etkilidir. Bireylerin ve grupların ilişkilerinin iyi olabilmesi için olumlu duygulara sahip olması gerekir (Turner ve Cameron, 2016). İnsanlar farklı gruplarla etkileşimde bulunduklarında bir dizi endişeye sahip olabilirler. Gruplararası kaygı, olumsuz duygulanım durumu olarak diğer grupla yaşanacak bir etkileşimde reddedilme, utanç verici duruma düşürülme hissi, huzursuzluk gibi hoş olmayan deneyimleri yaşama olasılığından kaynaklanan duygu olarak tanımlanmaktadır (Stephan ve Stephan, 
1985). Gruplararası kaygı kaçınma davranışına eşlik ederken ayrıca gruplararası etkileşimin doğasını, sıklığını ve düşmanca duyguların oluşumuna da etki edebilir (Plant ve Devine, 2008; Techakesari vd., 2015). Gruplararası kaygı yaşayan bireylerin gruplara yönelik önyargıya sahip oldukları belirtilmektedir. Ayrıca gruplarla yaşanan deneyimlerin, kalıplaşmış yargıların gruplararası kaygıya etki eden özellikler olduğu ifade edilmektedir (Stephan ve Stephan, 1985; Stephan, 2014). Dolayısıyla yapılan bu çalışmada bireylerin gruplararası kaygısının olduğu, bunun da çalışma kapsamına alınan bireylerin sığınmacı bireylere yönelik sahip olduğu olumsuz duygu ve önyargılar nedeniyle oluştuğunu düşündürmektedir.

Allport (1954) gruplararası etkileşimin temelinde farklı gruplarla birlikte yüzyüze etkileşimin gruplararası kaygıyı ve düşmanlığı azalttığını belirtir. Allport önyargının azaltılması için, gruplararası düşmanlığın, grupların birbirine yabancı ve uzak olmasından kaynaklandığı, uygun şartlar sağlandığında grup üyeleri arasındaki düşmanlığın azalacağı ve daha olumlu tutumların geliştirilebileceğini ifade etmektedir. Etkileşimin önyargıyı azalttığına yönelik literatür bilgisi birkaç çalışmada bulunmaktadır (Hewstone, 2015; O'Conner, 2017; Swart, Hewstone, Christ ve Voci, 2010). Bir çalışmada yerli Avusturyalıların mültecilere karşı etkileşimi ile önyarg1 arasındaki ilişkiye bakılmıştır. Etkileşimin kalitesi yüksek, olumlu ve iyi geliştirilirse gruplararası kaygı ve önyargının düştüğü saptanmıştır (Katrine, Turoy-Smith ve Anne, 2013). Diğer araştırma bulguları ve yapılan bu çalışmaya paralel olarak toplumun kendi grubu dişında farklı gruplarla etkileşimde bulunması bireylerde kaygıya neden olmaktadır. Gruplar hakkındaki bilinmezlik kişilerde önyargıya, kuşkuculuğa ve tehdit altında olmaya sebep olmaktadır. Yapılması gereken toplumun sığınmacılara yönelik mümkün olduğunca olumlu etkileşimde bulunmaya ve toplum olarak empati kurmaya çalışılması; toplumun sığınmacılar hakkındaki önyargılarının neler olduğunun fark ettirilmesi gerekmektedir. Bunun için toplumun bu konu ile ilgili bilgilendirilmesi, düzenli eğitim programlarının oluşturulması ve uygulamaya geçirilmesi önemli olacaktır.

Bu çalışmada kadınların erkeklere oranla sığınmacı bireylerle ilişkilerinde daha kaygılı oldukları saptanmıştır. Bunun nedeni ataerkil bir toplumda yaşıyor olmak, kadınların farklı bireylere karşı daha önyargılı, negatif ve kaygılı olmalarına neden olabilmektedir. Ayrıca ayrımcılığın 
meşru ve mantıklı hale gelmesinde etkili olan bir takım kavramlar bulunmaktadır. Bunlar kurbanın değersizleştirilmesi ve ötekileştirilmesi, ahlaki dışlama ve sistemin meşrulaştırılması, adil dünya inancı kuramıdır. Adil dünya inancı her şeyin bir sebebi ve karşılığının olduğuna yönelik inanıştır. Diğer bir ifadeyle adil dünya inancı yüksek olan kişiler, kişinin başına gelenleri hak ettiğine inanmaya yatkındırlar (Furnham, 2003; Göregenli, 2016). Yaşadığı kötü olay örneğin, sığınmacıların ülkelerinin işgalinin büyük olasılıkla vatanlarını korumadıkları içindir ve bu nedenle buradadırlar inancıdır. Kadınların, engelli bireylerin ve yaşlıların adil dünya inancının daha düşük olduğu belirtilmektedir. Çünkü bu grup adaletsizliği, ayrımcılığı daha fazla yaşamaktadır. Özellikle Türk toplumunda toplumsal cinsiyet eşitsizliğini ve ayrımcılığg kadının yaşamasına rağmen, ayrımcılı̆̆ı gösteren bir bulgu olan gruplararası kaygının kadınlarda yüksek olması ataerkil bir toplumun etkisinin hala sürdüğünü düşündürtmektedir. Bununla birlikte çoğunluğun düşünce yapısının da yani "grup etkisi"nin de toplumda baskın olduğu belirtilmektedir (Zimbardo, 2007). Ayrıca ayrımcılık yaşayan bireylerinde ayrımcı yaklaşımlar içinde olduğu vurgulanmaktadır (Çelik ve Şahin, 2012). Ek olarak da kadınlar daha çok hane içinde bulunmakta erkeklerse daha çok kamusal alandadırlar ve sığınmacılarla çok daha fazla temas etme olasılıkları vardır. Etkileşimde bulunma ve tanımaya çalışmak gruplararası kaygıyı azaltmaktadır. Kadınlarda gruplararası kaygının yüksek olması sığınmacılarla etkileşimlerinin az olabilmesinden kaynaklandığını düşündürmektedir.

Bu çalışmada kendisini Türk olarak ifade edenlerin gruplar arası kaygılarının daha yüksek olduğu saptanmış ve bizim çalışmamızı destekler nitelikte birkaç çalışmada çoğunluk grubun azınlık gruba yönelik gruplararası kaygılarının yüksek olduğu belirlenmiştir (Çelik ve Şahin, 2012; Finchilescu, 2010). Yapılan bu çalışmaya benzer bir çalışmada beyaz ve siyah olmak üzere İki farklı ırktaki öğrencilerin diğer ırktaki kişilere yönelik tutumlarına bakılmıştır. Beyaz Afrikalıların diğer ırktaki gruplarla etkileşimde iken kaygılarının yüksek olduğu ve beyaz öğrencilerin daha önyargilı olduğu belirlenmiştir (Finchilescu, 2010).

Bogardus'a (1925) göre sosyal mesafe, sosyal grupların birbirlerini algılanan yakınlık derecesine (komşuluk, arkadaşlık, evlilik gibi) göre sosyal değerlendirmesi ve onaylaması olarak ifade etmektedir. Bu yakınlık farklı dini, etnik ve ırktan gelen insanların diğer gruptan olan kişi ya da 
kişilerle komşuluk etmesi, arkadaş olması ya da evlenmesi gibi konularda ne derece kabul gördüğüne dayanmaktadır. Sosyal mesafenin az olması, bireyler ya da gruplar arasındaki yan yana yaşama isteği, birbirini sosyalleşme adına görme isteği, evlilik yapma, arkadaşlık kurma gibi bazı etkileşim alanlarında yakınlaşmaya işaret etmektedir. Sosyal mesafenin fazla olması etkileşim olasılığının düşük olduğunu, ev, okul ve iş hayatında bireylerin aralarına görüşme mesafesi koyduğunu göstermektedir. Bastian ve vd. (2012), sosyal mesafenin de önyargıların bir şekli olduğunu; ilişkiden kaçınma ya da değerlendirmeye ilişkin tutumların aynı yerden kök saldığını öne sürmektedir. Yine onlara göre azınlık bir grup için, çoğunluğa hissedilen sosyal mesafenin tepkileri ölçmede önemli bir etmen olduğunu belirtmektedirler.

$\mathrm{Bu}$ çalışmadaki bireylerin SMÖ madde toplam puan ortalamaları 19.96 \pm 7.82 'dir. Bireylerin SMÖ puan ortalamaları arttıkça sığınmacılara yönelik sosyal mesafelerinin az olduğunu, puan ortalamaları azaldıkça sığınmacılara yönelik sosyal mesafelerinin çok olduğunu göstermektedir. İncelendiğinde bu çalışmada bireylerin puan ortalamaları düşük olarak değerlendirilmektedir. Çalışmadaki bu verinin yapılan birkaç çalışma ile uyumlu olduğu görülmektedir. Bir çalışmada katılımcıların önemli bir kesimi kendilerine komşu olan Suriyeli sığınmacı istemediklerini, Suriyeli sığınmacıların kentte çok sayıda sorun oluşturduğunu düşündüklerini ve onlara hiçbir şekilde kiralık ev vermek istemediklerini belirtmişlerdir (Deniz, 2015). Oğuz'un yaptığı çalışmada da katılımcıların sığınmacılarla arkadaşlık ilişkilerinin olmadığı, onlara sosyal mesafe koydukları, genelde sığınmacılara karşı olumsuz düşünce ve duygu içinde oldukları saptanmıştır (Oğuz, 2015). Mercan Uzun ve Bütün'ün (2016) çalışmasında öğretmenlerin sığınmacı çocukları dil problemi nedeni ile istemedikleri belirlenmiştir. Göç alan toplumların mülteci ve sığınmacılara yönelik davranışları incelendiğinde, toplumların bu kişilere büyük oranda kültürel mesafe koydukları saptanmıştır (Aslan, 2015; Karaca ve Doğan, 2014; Oytun ve Gündoğar, 2015; Taşdemir, 2018; Zencir ve Davas, 2014).

Çalışmada sığınmacılara yönelik kadınların erkeklere oranla sosyal mesafelerinin daha fazla olduğu bulgulanmıştır. Benzer bir araştırmada da kişilerin cinsiyetinin sosyal mesafeye etkisinin olduğu belirtilmektedir (Yvonni and Longhi, 2012) Aksine Güler'in (2013) yaptığı bir çalışmada 
sosyal mesafe için cinsiyetin etkisinin Türk ve Kürt kökenli gruplar arasında anlamlı bir fark olmadığı belirlenmiştir. Polonyalıların diğer azınlıklara yönelik sosyal mesafelerinin ölçüldügü bir çalışmada da cinsiyetin etkisinin olmadığı saptanmıştır (Nowicka ve Krzyzowski, 2016). Bizim çalışmamızda kadınların erkeklere göre sosyal mesafelerinin daha fazla olması sığınmacılarla etkileşimlerinin, sosyal temaslarının az olmasından ve gruplararası kaygılarının yüksek olmasından kaynaklandığını düşündürmektedir.

Eğitim arttıkça sosyal mesafenin azaldığı yapılan çalışmalarda saptanmıştır (Markaki ve Longhi, 2012; Nowicka ve Krzyzowski, 2016). Yapılan bu çalışmada ise fark saptanmasına rağmen bu artış doğrusal değildir.

Bu çalışmada etnik kökenin SMÖ'ye etkisinin olduğu ve kendisini diğer azınlıkta bildirenlerin sığınmacılara yönelik sosyal mesafelerinin az olduğu saptanmıştır. Polonyalıların dini, etnik ve cinsiyet açısından azınlıktaki bireylere yönelik sosyal mesafelerine bakılan bir çalışmada, azınlıktaki bireylere yönelik Polonyalıların sosyal mesafelerinin yüksek olduğu bildirilmiştir (Nowicka ve Krzyzowski, 2016). Yine Türkiye'de yapılan bir çalışmada (Aslan, 2015) kendini Kürt olarak tanımlayanların Türk olarak ifade edenlere göre sığınmacılara yönelik sosyal mesafelerinin düşük olduğu saptanmış ve yapılan bu çalışmayla uyumlu bir sonuç alındığı belirlenmiştir.

Çalışma kapsamına alınan bireylerin yaşı, eğitimi, gelir ve çalışma durumu, en uzun yaşanılan yerin GKÖ’ye; yine katılımcıların yaşı, gelir ve çalışma durumu, en uzun yaşanılan yerin SMÖ'ye etkisinin istatistiksel olarak anlamlı olmadığı belirlenmiştir ( $p>0.05)$.

Gruplar arasında yüksek düzey kaygının bulunması hem sosyal mesafeyi hem de olumlu etkilerini sinırlamaktadır (Aberson, 2015; Stephan ve Stephan, 1985). Gruplararası kaygının azalmasıyla arkadaşlık mekanizmasının daha etkili olacağı ve önyargıların azalacağı, sosyal mesafenin nasıl bir etkide bulunacağının kaygı ile belirlendiği, kaygı yaşayacaklarını düşünen azınlık grubu üyelerinin sosyal mesafeyi arttırdığı, kaygı duyulmayan bir gruplararası ilişkide ise olumlu duyguların arttığı öne sürülmektedir (Aberson, 2015; Binder vd., 2009; Turner, Hewstone, Voci, Paolini ve Christ, 2008; Vonofakou, Hewstone ve Voci, 2007). Çalışmaya katılan bireylerin GKÖ ve SMÖ puan ortalamaları arasında pozitif yönde bir korelasyon olduğu saptanmıştır. Diğer bir ifadeyle sığınmacılara yönelik 
duyulan kaygı arttıkça bireylerin sosyal mesafeleri de artmaktadır. Güler'in (2013) gruplararası temas, kaygı ve yanlılığın sosyal mesafeye etkisini incelediği araştırma ile bu çalışmada elde edilen bulgular paralellik göstermektedir. Ayrıca literatürdeki birkaç çalışma da sosyal temasın gruplar arasındaki kaygıyı ve sosyal mesafeyi azalttığını da göstermektedir (Barlow, Louis ve Terry, 2009, 2010; Küçükkömürler ve Sakallı Uğurlu, 2017; Pettigrew, 1998; Turner, Hewstone, Voci, Paolini ve Christ, 2008).

Bu bulgular doğrultusunda bireylerin GKÖ ve SMÖ puan ortalamalarının düşük olduğu; sosyodemografik özelliklerinin gruplararası kaygı düzeyine ve sosyal mesafeye etkisinin olduğu; gruplararası kaygı düzeyi arttıkça sosyal mesafelerinin arttığ saptanmış ve H1, H2, H3 hipotezleri desteklenmiştir.

\section{Sonuç ve Öneriler}

Bu çalışmada toplumun sığınmacı bireylerle ilgili duygu ve düşüncelerini ortaya koymak için bireylerin gruplararası kaygı ve sosyal mesafeleri incelenmiştir. Çalışmaya alınanların GKÖ ve SMÖ puan ortalamalarının düşük olduğu saptanmıştır. Yine katılımcıların sosyodemografik özelliklerinin gruplararası kaygı düzeyine ve sosyal mesafeye etkisi olduğu belirlenmiştir. Bireylerin gruplararası kaygı düzeyi arttıkça sosyal mesafelerinin arttığ 1 ve aralarında pozitif yönde bir ilişkinin olduğu bulunmuştur. Bu bulgular ışığında çalışmaya alınan bireylerin sığınmacılara yönelik duygu ve düşüncelerinin olumsuz, önyargılı ve ayrımcı eğilim içinde olduğu düşünülmektedir.

Her temas önyargıyı azaltmayabilir, bazı durumlarda temas, tehdit unsurunu da içeriyorsa önyargıları doğurabilir. Bu nedenle sığınmacılarla olan temasın sağlıklı bir ortamda olabilmesi önemlidir. Sığınmacılar özellikle Suriyeli sığınmacılar artık Türkiye'nin gerçeği ise bunun olumsuz etkilerini azaltacak olumlu etkiler üzerinde durulması gerekmektedir. S1ğınmacılar konusu toplumsal uyum sorunu olarak ele alınmalı; çalışma hayatı, eğitim, barınma, sağlık ve belediye hizmetleri gibi toplumun alıştırılmasına yönelik bir politika geliştirilmelidir.

Sığınmacılara yönelik toplumun kafasındaki olumsuz duygu ve düşüncelerin ortadan kalkması için topluma empatinin öneminden bahsetmeye yönelik eğitimlerin ve çalışmaların yapılmasının oldukça önemli 
olacağı düşünülmektedir. Bunun için anasınıfı ile başlayıp ilkokul, ortaöğretim, üniversite eğitimi ile devam edecek şekilde gençlere kendini tanıma, empati, farkındalık, iletişim becerileri ve kendisi dışındaki insanların hiçbir ülkeye, dine, etnik kökene, cinsel yönelimine, cinsiyetine ve sağlık durumuna bağlı kalmaksızın yalnızca birey oldukları için önemli olduklarına yönelik bir eğitimin yaşama geçirilmesinin önemli olduğu düşünülmektedir.

\section{Sinırlılıklar}

Yapılan çalışma sadece bir şehirdeki çalışma kapsamına alınan bireylerin sığınmacılara yönelik duygu ve düşüncelerini göstermektedir, dolayısıyla toplumdaki tüm bireylerin tutumlarını göstermeyebilir. Ayrıca bu çalışmaya alınan bireylerin daha önce sığınmacılarla herhangi bir etkileşimde olup olmadıklarına ve sığınmacılar hakkındaki kalıp yargılarına dair herhangi bir bilgi alınmamıştır. Yapılacak olan çalışmalar için bu özelliklerinde üzerinde durulması oldukça önemli olacaktır.

\section{Çıkar Çatışması}

Yazarlar bu makale ile ilgili olarak herhangi bir çıkar çatışması bildirmemişlerdir. 


\title{
EXTENDED ABSTRACT
}

\section{Determination of Social Distance and Anxiety Situations of the Society about Asylum Seekers}

\author{
Gülay Taşdemir Yiğitoğlu - Bilgin Kıray Vural \\ * \\ Pamukkale University
}

\section{Introduction}

According to the 1951 Geneva Convention definition of the term 'refugee' which is used by international law today, a "Refugee is a person who owing to a well-founded fear of being persecuted for reasons of race, religion, nationality or being part of a particular social group or political opinion, is outside the country of citizenship and is unable or, owing to such fear" unwilling to return to their country of citizenship. 'Asylum-seeker' is a term used for a person who, in general, has left their country of origin and formally applied for asylum in another country but whose application has not yet been decided. This term is also used for people who have not yet applied or people waiting for the result of an application. In a sense asylum is a process, while refugeedom is a status, that is to say it is the result (GİGM, 2016; Urk, 2010). According to these definitions, the term asylum-seeker has been approved for people who are forced to emigrate to another country and the concept of 'asylum' was adopted for this study.

The war and violence that have been going on in the Middle East since 2003 also affect neighboring countries. This situation has caused major social displacement (City Limits, 2015). War is a global health problem (Singer \& Hodge, 2010). Wars cause long term effects of death, injury, illness that affect the whole lives of survivors (UNPF, 2014). Additionally, wars lead to migrations of masses of people to other countries. To date, approximately 65.3 million people have been displaced because of wars in the World. Approximately 21.3 million of these asylum-seekers are under 18 and 10 million people are stateless; they are deprived of their most basic rights to food, drink, accommodation, health and education. Almost 
258,000 asylum-seekers and refugees (121,000 Iraqis and 98 thousand Afghans) have migrated to other countries (UNHCR, 2017).

When examining the attitudes of immigrant-receiving societies towards asylum-seekers, it is commonly seen that societies maintain a large cultural distance from asylum-seekers. This may be because of demographical anxiety, fear of the loss of revenue or anxiety relating to economic hardship due to rising home prices. The idea that asylum-seekers represent a burden on social services and cause distruption in public services is also widespread. Asylum-seekers are also often seen as the cause of disease and crime and consequently people feel distrust towards them. This perspective creates difficulties for asylum-seekers in social integration (Erdoğan, 2014; Karaca \& Doğan, 2014; Oytun \& Gündoğar, 2015; Y11diz, 2013; Zencir \& Davas, 2014). This can create social distance vis-a-vis asylum-seekers and cause social anxiety while interacting with them.

Social distance is a concept that shows the hierarchical relationships of any individual belonging to a particular social class with other classes, groups and individuals, the relationships between classes within a population, and social differences in relationships among specific populations (Bogardus, 1925). Social distance in social psychology is the degree of acceptance or rejection of the members of different social groups taking factors such as race, religion, and nationality into account (Marshall, 1999).

Intergroup anxiety is described as a negative mood arising from the possibility of having unpleasant experiences such as being rejected in interaction with another group, entering into an embarrassing situation and restlessness (Stephan \& Stephan, 1985).

In this study, concrete data will be obtained about the feelings and thoughts of members of Turkish society about asylum-seekers by measuring anxiety status and social distance. This study will provide information on society's opinion about individuals who are considered to be long-term residents in Turkey and on the more positive attitudes that need to be fostered in order to live more healthily and happily with these individuals. It is thought that asylum-seekers will be a part of the life of Turkish people in the long term, so this study will contribute to the field of future practise, particularly as there is a limited number of studies of Turkish society attitudes to asylum-seekers. 
The aim of this study is to determine the feelings and thoughts of society towards asylum-seekers.

This study used a descriptive and cross-sectional study design in order to examine the feelings and thoughts of society towards asylum-seekers. The research data were collected between June and September 2016 in Denizli, Turkey.

The research population consisted of individuals older than 18 living in Denizli. Random sampling (convenience accidental sampling) was used as the sampling method. Data were obtained by means of face-to-face interviews with individuals who agreed to participate in the survey. The data were collected by pollsters; due to the sensitive subject matter of the research it was based on volunteerism.

The instruments used in the study were as follows: a questionnaire form measuring demographic information, the Intergroup Axiety Scale (IAS), and the Social Distance Scale (SDS).

The analysis of the data was performed using the SPSS 15.0 (Statistical Package for Social Sciences) software package and involved examining number and percentage distribution of data, student's t-test, variance analysis, and internal consistency for Cronbach's Alpha reliability coefficient.

In this study, the anxiety and social distances between the groups of the individuals were examined in order to reveal the feelings and thoughts of the society regarding the asylum-seekers. It was determined that the average IAS and SDS scores were lower for the participants of the study. It was also determined that the socio-demographic characteristics of the participants have influenced the level of the anxiety and social distance between the groups. As the individuals' level of anxiety between the groups have increased, it was found that their social distances have increased and there has been a positive relationship between them. Under the light of these findings, it can be said that the feelings and thoughts of the individuals, who have participated in this study, to the asylum-seeker are in a negative, prejudiced and discriminating tendency.

If the asylum-seekers, especially Syrian asylum-seekers, have become reality of Turkey, it is now required to take the positive impacts, which will downgrade the negative effects, into consideration. Those who want to return to their country should be encouraged and sent to their countries. 
If they do not wish to go, then the country should implement a policy that envisages asylum-seekers. The issue of asylum-seekers should be considered as a matter of social cohesion and the policy should be developed by organizing the areas such as working life, education, housing, health, municipal services, and community adaptation.

In addition, the media's influence on society, the education system, attitudes towards different groups that make up the society in the general functioning of the working life, and in general, on the processes of following the majority, behaving in the same direction with the majority and obeying in a society plays a positive or negative role in diminishing the prejudice and the discrimination. For this reason, handling the intergroup relations in a way that is more friendly, equalitarian, and non-promoting the stereotypes, will make the media have an important role in reducing the discrimination.

Organizing trainings to tell the society about the significance of the social empathy in order to get rid of the negative emotions and thoughts within the minds of the community and especially media's being an agent for these trainings. To be the vehicle of media especially for these trainings can be of extreme importance.

Every contact may not reduce the prejudice, and in some cases contacts may result in creating prejudices if the contacts involve threats. For this reason, it might be very important to develop policies to ensure that the contact with asylum-seekers is in a healthy environment.

Negative emotions and thoughts of the society towards asylum seekers should be eliminated. For this, it is thought that it will be very important to make trainings and studies about the importance of empathy to the society.

This study shows the feelings and thoughts of individuals in only the study group and therefore it cannot show the attitudes of all individuals in society. Also, we did not have information regarding whether participants in this study had had interactions with asylum-seekers before or not or whether they had stereotype about asylum-seekers. Future studies will need to focus on these features. 


\section{Kaynakça / References}

Allport, G. W. (1954). The nature of prejudice. Garden City, NY: Doubleday. Aberson, C. L. (2015). Positive intergroup contact, negative intergroup contact, and threat as predictors of cognitive and affective dimensions of prejudice. Group Processes \& Intergroup Relations, 18(6), 743-760.

Aslan, C. (2015). Zorunlu ev sahipliği sürecinden komşuluk sürecine: Yerel halkın Suriyeli sığınmacılara karşın yaşantı, algı, tutum ve beklentilerinin tespiti:Adana Örneği. 4. Türkiye Nüfusbilim Kongresi Bildiri Kitapçı̆̆ı içinde (207-231), 5-6 Kasım 2015, Ankara.

Barlow, F. K., Louis, W. R. ve Hewstone, M. (2009). Rejected! Cognitions of rejection and intergroup anxiety as mediators of the impact of cross-group friendships on prejudice. British Journal of Social Psychology, 48(3), 389-405.

Barlow, F. K., Louis, W. R. ve Terry, D. J. (2010). Minority report: Social identity, cognitions of rejection and intergroup anxiety predicting prejudice from one racially marginalized group towards another. European Journal of Social Psychology, 40(5), 805-818.

Bastian, B., Lusher, D. ve Ata, A. (2012). Contact, evaluation and social distance: Differentiating majority and minority effects. International Journal of Intercultural Relations, 36, 100-107.

Binder, J., Zagefka, H., Brown, R., Funke, F., Kessler, T., Mummendey, A., ... Leyens, J. P. (2009). Does contact reduce prejudice or does prejudice reduce contact? A longitudinal test of the contact hypothesis among majority and minority groups in three European countries. Journal of Personality and Social Psychology, 96 (4), 843-856.

Bogardus, E. S. (1925). Measuring social distance. Journal of Applied Sociology, 9, 299-308.

Chronicle, F. (1 Nisan 2015). Hardship inside Assad's Land. Retrieved from https://chronicle.fanack.com/syria/history-past-to-present/hardship-inside-assads-land/ on (30 Nisan 2016).

City limits. (2015). Urbanisation and vulnerability in Sudan Khartoum case study. HPG Commissioned Report group. 
Çelik, A. ve Şahin E. (2012). Ötekilerin hiyerarşisinde kültürel ve sınıfsal karşılaşmalar: Kürt toplumunda Çingene algısı ve sosyal dişlanma, Toplum ve Kuram, 6-7, 307-325.

Deniz, C. (2015). Zorunlu göçün mekânsal etkileri ve yerel halkın algısı: Kilis örneği, International Periodical for the Languages, Literature and History of Turkish or Turkic, 10(2), 101-122.

Erdoğan, M. M. (2014). Türkiye'deki Suriyeliler: Toplumsal kabul ve uyum araştırması, Ankara: Hacettepe University Immigration and Political Research Center.

Finchilescu, G. (2010). Intergroup anxiety in interracial interaction: The role of prejudice and metastereotypes. Journal of Social Issues, 66(2), 334-351.

Furnham, A. (2003). Belief in a just world: Research progress over the past decade. Personality and Individual Differences, 34(5), 795-817.

Göç İdaresi Genel Müdürlüğü (GIGM). (2016). Türkiye ve göç. Retrieved from http://www.goc.gov.tr/files/files/goc_tasar\%C4\%B1m_icler.p on (25 Mayis 2016).

Göregenli, M. (30 Temmuz 2016). Ayrımcılı̆̆ın meşrulaştırılması. Retrieved from http://secbir.org/images/haber/2011/01/06-melek-goregenli2.pdf on (29 Haziran 2017).

Güler, M. (2013). Gruplararası temas, kaygı ve yanlılı̆̆ın sosyal mesafeye etkisi: Türk ve Kürt kökenli gruplar üzerine bir çalışma. Phd diss., Ankara University Social Science Institude Department of Pyschology,Social Pyschology, Ankara.

Güngör, M. (2014). Okul öncesi dönem çocuklarının televizyon izleme alışkanlıkları ve anne baba tutumları, Mustafa Kemal Üniversitesi Sosyal Bilimler Enstitüsü Dergisi, 11(28), 199-216.

Hewstone, M. (2015). Missing dimension of intergroup contact. Journal of Social Issues, 71(2), 417-438.

Karaca, S. ve Doğan, U. (2014). Suriyeli göçmenlerin sorunları çalıştayı sonuç raporu [The final report of syrian immigrants problems workshop]. Mersin: Mersin University Regional Monitoring and Application Research Center. 
Karakaş, B. (2014). Sığınmacılar kamp istemiyor. [Asylum-seekers do not want Camp]. Retrieved from. http://www.milliyet.com.tr/siginmacilarkampistemiyor/gundem/detay/1862821/default.htm on (5 Nisan 2017).

Katrine, M., Turoy-Smith, R. K. ve Anne, P. (2013). The willingness of a society to act on behalf of Indigenous Australians and refugees: The role of contact, intergroup anxiety, prejudice, and support for legislative change. Journal of Applied Social Psychology, 43, 179-195.

Kesgin, H. (2014). The bitter truth behind Syrian War: Desperate widows. Retrieved from http://www.aa.com.tr/en/news/285989--the-bittertruth-behind-syrian-war-desperate-widows on (2 Mayis 2016).

Küçükkömürler, S. ve Sakallı Uğurlu, N. (2017). Gruplar arası ilişkileri düzenlemede sosyal temas kuramları: Gruplar arası, yayılmacı ve hayali temas. Nesne Psikoloji Dergisi, 5(9), 1-31.

Magee, J. C. ve Smith, P. K. (2013). The social distance theory of power. Personality and Social Psychology Review, 17(2), 158-186.

Markaki, Y. ve Longhi, S. (2012). What determines attitudes to immigration in European countries? An analysis at the regional level. London: Norface Migration Discussion Paper No. 32.

Marshall, G. (1999). Sociology Dictionary. (O. Akınhay ve D. Kömürcü Eds.), Ankara: Science and Art Publications.

Mercan-Uzun, E. ve Bütün, E. (2016). Okul öncesi eğitim kurumlarındaki Suriyeli sığınmacı çocukların karşılaştıkları sorunlar hakkında öğretmen görüşleri [Teachers' views on 1ssues faced Syrian preschool asylum-seekers children]. Uluslararası Erken Çocukluk Eğitimi Çalışmaları Dergisi, 1(1), 72-83.

Nowicka, M. ve Krzyżowski, L. (2016). The social distance of poles to other minorities: A study of four cities in Germany and Britain. Journal of Ethnic and Migration Studies, 6(23), 1-20.

O'Connor, A. (2017). The Nature of Prejudice. London: Macat Library.

Oğuz, H. Ş. (2015). Kültürlerarası karşılaşmaların uzak ihtimali: Sığınmacılık deneyiminde Gaziantep örneği [Remote possibility of intercultural encounters: Example of Gaziantep in experience of asylum-seeker]. Tesam Akademi Dergisi, 2 (2), 127-165. 
Oytun, O. ve Gündoğar, S. S. (2015). Suriyeli sığınmacıların Türkiye'ye etkileri raporu [The report of effects of Syrian asylum-seekers to Turkey]. Ankara: ORSAM- TESEV Report No: 195.

Pettigrew, T. F. (1998). Intergroup contact theory. Annual Review Psychology, 49, 65-85.

Plant, E. A. ve Devine, P. G. (2008). Interracial interactions: Approach and avoidance. In (A. J. Elliot Ed.), Handbook of approach and avoidance motivation (p. 571-584). NewYork: Psychology Press.

Singer, M. ve Hodge, G. D. (2010). The war machine and global health: A critical medical anthropological examination of the human costs of armed conflict and the international violence industry. United States of America: AltaMira Press.

Stephan, W. G. (2014). Intergroup anxiety: Theory, research, and practice. Personality and Social Psychology Review, 18(3), 239-255.

Stephan, W. G. ve Stephan, C. W. (1985). Intergroup anxiety. Journal of Social Issues, 41, 157-175.

Stephan, W. G. ve Stephan, W. C. (1996). Intergroup relations. Boulder, CO: Westview Press.

Swart, H., Hewstone, M., Christ, O. ve Voci, A. (2010). The impact of crossgroup friendships in South Africa: Affective mediators and multigroup comparisons. Journal of Social Issues, 66, 309-333.

Taşdemir, N. (2018). Ulusal kimliğin sınırlarını tanımlama biçimleri ve Türkiye'ye gelen Suriyeli sığınmacılara yönelik tutumlar. Türk Psikoloji Yazıları, 21(Özel Sayı), 3-18.

Techakesari, P., Barlow, F. K., Hornsey, M. J., Sung, B., Thai, M. ve Chak, J. L. Y. (2015). An investigation of positive and negative contact as predictors of intergroup attitudes in the United States, Hong Kong, and Thailand. Journal of Cross-Cultural Psychology, 46(3), 454468.

Turner, R. N. ve Cameron, L. (2016). Confidence in contact: A new perspective on promoting cross-group friendship among children and adolescents. Social Issues and Policy Review, 10 (1), 212-246.

Turner, R. N., Hewstone, M., Voci, A., Paolini, S. ve Christ, O. (2008). Reducing prejudice via direct and extended cross-group friendship. In (W. Stroebe, and M. Hewstone Eds.), European Review Of Social Psychology (p. 212-255). Hove, E. Sussex: Psychology Press. 
United Nations Population Fund (UNPF). (2014) Migration: A world on the move. Accessed on 30.11.2017 Retrieved from http://www.unfpa.org/pds/migration.html

UNHCR The UN Refugee Agency. (2017). Note on legal considerations for cooperation between the european union and Turkey on the return of asylum-seekers and migrants. Accessed on 30.11.2017 Retrieved from http://www.unhcr.org/protection/operations/56f3af909/note-legal considerations-cooperation-european-union-turkey-return-asylum.html?query

Urk, M. (2010). Göç olgusu bağlamında mülteciler, sığıımacılar ve insan hakları [Migration in the context refugees, asylum-seekers and human rights]. Postgraduate Thesis, Maltepe University Social Science Institution, İstanbul.

Vonofakou, C., Hewstone, M. ve Voci, A. (2007). Contact with out-group friends as a predictor of meta-attitudinal strength and accessibility of attitudes toward gay men. Journal of Personality and Social Psychology, 92(5), 804-820.

Yıldız, Ö. (2013). Türkiye kamplarında Suriyeli sığınmacılar: Sorunlar, beklentiler, Türkiye ve gelecek algısı." [Syrian asylum-seekers in camps in Turkey: Problems, expectations, Turkey and future concerns]. Sosyoloji Araştırmaları Dergisi, 11, 41-167.

Yvonni, M. ve Longhi, S. (2012). What determines attitudes to immigration in European countries? An analysis at the regional level. NORFACE Migration Discussion Paper No 2012-32. Retrieved from http://www.norface-migration.org/publ_uploads/NDP_32_12.pdf.

Zencir, M. ve Davas, A. (2014). Suriyeli sığımmacılar ve sağlık hizmetleri raporu. [Syrian asylum-seekers and health service report]. Ankara: Türk Tabipleri Birliği.

Zimbardo, P. (2007). Şeytan etkisi, kötülüğün psikolojisi. İstanbul: Say Yayınlar1. 


\section{Kaynakça Bilgisi / Citation Information}

Yiğitoğlu-Taşdemir, G. ve Vural-Kıray, B.(2019). Toplumun sığınmacı bireylerle ilgili sosyal mesafe ve kayg1 durumlarının belirlenmesi. OPUS-Uluslararası Toplum Araştırmaları Dergisi, 11(18), 1941-1696. DOI: 10.26466/opus. 545074 